\title{
Hand hygiene knowledge and practice among university students: evidence from Private Universities of Bangladesh
}

This article was published in the following Dove Press journal:

Risk Management and Healthcare Policy

I2 February 2016

Number of times this article has been viewed

\author{
Marufa Sultana' \\ Rashidul Alam Mahumud' \\ Abdur Razzaque Sarker ${ }^{\prime}$ \\ Sarder Mahmud Hossain ${ }^{2}$ \\ 'Health Economics and Financing \\ Research Group, Centre for \\ Equity and Health System (CEHS), \\ International Centre for Diarrhoeal \\ Disease Research, Bangladesh, \\ ${ }^{2}$ Department of Public Health, \\ Northern University Bangladesh, \\ Dhaka, Bangladesh
}

\begin{abstract}
Hand hygiene has achieved the reputation of being a convenient means of preventing communicable diseases. Although causal links between hand hygiene and rates of infectious disease have also been established earlier, studies focusing on hand hygiene among universitygoing students are not adequate in number. This study evaluated handwashing knowledge, practice, and other related factors among the selected university students in the city of Dhaka, Bangladesh. A cross-sectional study was conducted among 200 undergraduate students from four selected universities. A pretested, semistructured questionnaire, that included a checklist associated with handwashing practice, was applied to capture all relevant data. The mean $( \pm S D)$ age of the participants was $20.4( \pm 1.8)$ years. The majority of the students washed their hands with water, but only $22.5 \%$ washed their hands effectively by maintaining the correct steps and frequency of handwashing with water, and soap or hand sanitizer. The mean $( \pm \mathrm{SD})$ score of the participants' hand hygiene practice was $50.81( \pm 4.79)$, while the total score with all perfect answers was considered as 66 . Regression coefficient demonstrated that age has a negative influence on hand hygiene practice, as older students have lower scores compared to the younger ones $(P<0.01)$. However, the unmarried students were a significant predictor for influencing the incensement of handwashing practice compared to the married ones $(P<0.01)$. Findings of this study designate widespread insufficient hand hygiene practice in the university-going students and indicate a need for an extensive public health education program on this topic. Furthermore, availability of soap and sufficient water supply is needed within the university setting to facilitate handwashing. Therefore, supporting quantity and quality of available campus-based public health education programs along with providing health-washing equipment is suggested.
\end{abstract}

Keywords: hand hygiene, hand washing, practice, university students

\section{Introduction}

Hand hygiene is a milestone of infectious disease control, and promotion of improved hand hygiene has been recognized as an important public health measure. ${ }^{1,2}$ It has long been recognized to be a convenient, effective, and also cost-effective means of preventing communicable diseases. ${ }^{2}$ According to the definition of World Health Organization, hand hygiene is a general term referring to any action of hand cleansing, ie, it is the act of cleaning one's hands with or without the use of water or another liquid, or with the use of soap, for the purpose of removing soil, dirt, and/or microorganisms. ${ }^{3}$ A causal link between hand hygiene and rates of infectious disease illness has also been established earlier., ${ }^{4,5}$ Globally, $>3.5$ million children younger than 5 years, ${ }^{6,7}$ mainly concentrated in developing countries ${ }^{8}$ including Bangladesh, die from diarrhea and acute lower respiratory tract infections. The transmission of communicable
Correspondence: Marufa Sultana International Centre for Diarrhoeal Disease Research, 68 Shaheed Tajuddin Ahmed Sharani, Mohakhali, Dhaka 1212, Bangladesh

Tel $+8802982700 I 10$ ext 2524

Fax +88028811568

Email marufa@icddrb.org 
diseases is responsible for $>164$ million lost school days per school year among students up to twelfth grade worldwide. ${ }^{9}$ Approximately 2.4 million deaths can be prevented annually by good hygiene practice, reliable sanitation, and drinking water. ${ }^{10}$ A meta-analysis on 30 hand hygiene studies found that improvements in handwashing reduced the incidence of upper respiratory tract infections by $21 \%$ and gastrointestinal illnesses by $31 \% .{ }^{11}$ Another evidence showed that handwashing with soap could reduce the risk of diarrheal diseases by $42 \%-47 \%$, and handwashing promotion could save millions of lives. ${ }^{12}$

Despite the proven importance and benefits of washing hand, proper handwashing is not as pervasive as desired to prevent infections until now, especially in the developing countries that bear the greatest burden of infectious diseases. A survey undertaken in Bangladesh indicated that handwashing practice with soap before eating was much lower than after defecation, and a gap persists between perception and practice of proper handwashing practices with soap. ${ }^{10}$ Another observational study in rural Bangladesh showed that $14 \%$ of all persons washed both hands with soap after defecation, while $<1 \%$ used soap and water for washing hand before eating. ${ }^{13}$ Several studies addressed hand hygiene among different population in Bangladesh; however, hand hygiene studies among college or university students are very limited. ${ }^{10,13,14}$ Although the morbidity and mortality associated with respiratory and gastrointestinal illnesses among university students are relatively low, these infections may contribute to absenteeism along with sickness presenteeism, which can ultimately affect academic performance and efficiency ${ }^{15}$ and can also be associated with outbreaks of viral gastroenteritis, upper respiratory tract infections, and group B streptococcal colonization in this setting, ${ }^{15}$ which ultimately affect potential human resource development. With the limited research about hand hygiene knowledge and practice among university students, this study evaluated handwashing knowledge, attitude, practice, and other related factors among the selected university students of Dhaka city in Bangladesh.

\section{Methods}

\section{Study design and setting}

A cross-sectional study was conducted among the undergraduate private university-going students in Banani of Dhaka city during August 2013-September 2013. Banani is an affluent residential area with a number of restaurants, universities, and shopping centers, as well as schools and members' clubs, in Dhaka, the capital of Bangladesh. Out of nine private universities located in Banani, Dhaka, four nearby universities are purposively selected for this survey. The universities were selected based on the criteria that must have undergraduate course level. The inclusion criterion for participants was being a registered undergraduate ongoing student of any year of bachelor level; and the participation was completely voluntary. Study participants provided written consent prior to participating; and participants' anonymity and confidentiality were maintained throughout the study. This study was conducted through Northern University where only written consent from participants was required and no IRB was applicable for this study.

\section{Sample size estimation}

An earlier study showed that $72.9 \%$ of the overall college students washed their hands. ${ }^{16}$

The following formula has been used for calculating sample size:

$$
\mathrm{n}=\frac{z^{2} p(100-p)}{d^{2}}
$$

where $\mathrm{n}$ is the required sample size, $d$ the marginal error level (we considered the proportion of handwashing practice of students at $6.5 \%$ proportion of marginal error level), and $z$ the standard normal deviate (considered 1.96 for $95 \%$ confidence interval $[\mathrm{CI}])$. The formula provided that the significant sample size was 180 . Considering a $10 \%$ nonresponse rate to the survey, the total required sample size was 198. Finally, a total of 200 participants who were willing to give written consent and participate in the study, were interviewed.

\section{Instruments and procedure}

A pretested, semistructured, interviewer-administrated questionnaire was applied to capture all relevant data related to sociodemographic characteristics, attitude toward hand hygiene, knowledge, as well as practice of hand hygiene. A checklist related to handwashing practice was incorporated into the questionnaire with three different responses. ${ }^{6}$ We put an assumed number " 3 " for every appropriate answer, " 2 " for the less appropriate, and finally " 1 " for no/wrong practice according to responses during analysis and then summed up to make the handwashing practice "score".

\section{Data analysis}

Descriptive statistics was used to summarize the data. The characteristics of the study participants were expressed in terms of mean, standard deviation (SD), percentage, and frequencies with 95\% CI. Multiple linear regression analysis was done to examine the effect of handwashing practice 
score on sex, age, marital status, educational status, parents' educational status, household size, and present living conditions among the study participants. The regression model is as follows for each variable:

$$
\begin{aligned}
y= & \beta_{0}+\beta_{1} x_{1}+\beta_{2} x_{2}+\beta_{3} x_{3} \\
& +\beta_{4} x_{4}+\beta_{5} x_{5}+\beta_{6} x_{6}+\beta_{7} x_{7}+\epsilon
\end{aligned}
$$

where $y$ is a dependent variable (total handwashing practice score), $x_{1}$ the respondents' age group ( $0=\leq 19$ years, $1=19$ 20 years, and $3=23$ years or older), $x_{2}$ the sex of respondents $(0=$ male and $1=$ female $), x_{3}$ the marital status of respondents $(0=$ married and $1=$ unmarried $), x_{4}$ the respondents' education level $(0=$ first year, $1=$ second year, $2=$ third year, and $3=$ fourth year), $x_{5}$ the education level of respondents' mother ( $1=$ up to primary, $2=$ secondary, $3=$ higher secondary, and $0=$ higher $), x_{6}$ the household size $(0=$ less than four members, $1=$ four to five members, and $2=$ more than five members), $x_{7}$ the living condition ( $0=$ with family member, $1=$ with relatives, $2=$ hostel or with friends, and $3=$ others), $\beta_{0}$ the unknown intercept, $\beta_{i}$ the unknown regression coefficient $(i=1,2,3,4,5,6$, and 7$)$ for each independent variable that refers to the effect of $x_{i}$ on total handwashing practice score, and $\in$ the error term. Unadjusted and adjusted regression coefficient and their corresponding 95\% CI and $R^{2}$ values were computed. For all tests conducted in this study, statistically significant level was accepted at $P<0.05$. All statistical analyses were performed using Stata 13.0.

\section{Results}

\section{Background information of participants}

A total of 200 students participated in the study (Table 1). Among the total, $68.5 \%$ of the respondents were male and $27.5 \%$ were married. The mean age $( \pm S D)$ was 20.4 $( \pm 1.8)$ years, and the age range was between 17 and 26 years. Approximately $51 \%$ of the participants were in the second year, followed by $19 \%$ in the third year. The study revealed that most of the respondents lived with their own family $(57.7 \%)$, whereas others lived in the hostel (26\%) and with relatives $(14 \%)$. With regard to parents' education, most of the parents had higher secondary level education and above (Table 1).

\section{General attitude and knowledge toward hand hygiene}

Majority of the students $(43.5 \%)$ washed their hands only three to five times daily, followed by $28.5 \%$ six to ten times. Only $22.5 \%$ among the total respondents washed their hands

\begin{tabular}{|c|c|c|}
\hline Variables & n (\%) & $95 \% \mathrm{Cl}$ \\
\hline Age $(y r s)($ mean $\pm S D)$ & $20.4 \pm 1.8$ & $(20.1,20.6)$ \\
\hline \multicolumn{3}{|l|}{ Age group } \\
\hline$<19$ years & $30(15.0)$ & $(10.7,20.7)$ \\
\hline $19-20$ years & $94(47.0)$ & $(40.1,54.0)$ \\
\hline $21-22$ years & $5 I(25.5)$ & $(19.9,32.1)$ \\
\hline$\geq 23$ years & $25(12.5)$ & $(8.6,17.9)$ \\
\hline \multicolumn{3}{|l|}{ Sex } \\
\hline Male & 137 (68.5) & $(61.7,74.6)$ \\
\hline Female & $63(31.5)$ & $(25.4,38.3)$ \\
\hline \multicolumn{3}{|l|}{ Marital status } \\
\hline Married & $55(27.5)$ & $(21.7,34.2)$ \\
\hline Unmarried & 145 (72.5) & $(65.8,78.3)$ \\
\hline \multicolumn{3}{|l|}{ Religion } \\
\hline Muslim & $|3|(65.5)$ & $(58.6,71.8)$ \\
\hline Non-Muslim & $69(34.5)$ & $(28.2,4 I .4)$ \\
\hline \multicolumn{3}{|l|}{ Educational status } \\
\hline First year & $29(14.5)$ & $(10.2,20.1)$ \\
\hline Second year & $102(51.0)$ & $(44.0,57.9)$ \\
\hline Third year & $38(19.0)$ & $(14.1,25.1)$ \\
\hline Fourth year & $31(15.5)$ & $(I I . I, 2 I .3)$ \\
\hline \multicolumn{3}{|l|}{ Mother's education } \\
\hline Up to primary & $32(16.0)$ & $(11.5,21.8)$ \\
\hline Secondary & $44(22.0)$ & $(16.8,28.3)$ \\
\hline Higher secondary & $81(40.5)$ & $(33.9,47.5)$ \\
\hline Higher & $43(2 \mid .5)$ & $(16.3,27.8)$ \\
\hline \multicolumn{3}{|l|}{ Father's education } \\
\hline Up to primary & $21(10.5)$ & $(6.9,15.6)$ \\
\hline Secondary & $20(10.0)$ & $(6.5,15.0)$ \\
\hline Higher secondary & 78 (39.0) & $(32.4,46.0)$ \\
\hline Higher & $81(40.5)$ & $(33.9,47.5)$ \\
\hline \multicolumn{3}{|l|}{ Household size, n } \\
\hline$<4$ & $32(16.0)$ & $(11.5,21.8)$ \\
\hline $4-5$ & $152(76.0)$ & $(69.5,81.5)$ \\
\hline$>5$ & $16(8.0)$ & $(4.9,12.7)$ \\
\hline \multicolumn{3}{|l|}{ Living condition } \\
\hline With family & II 5 (57.5) & $(50.5,64.2)$ \\
\hline With relatives & $28(14.0)$ & $(9.8,19.6)$ \\
\hline Hostel or with friends & $52(26.0)$ & $(20.3,32.6)$ \\
\hline Others & $5(2.5)$ & $(1.0,5.9)$ \\
\hline Monthly household income & $38,345 \pm \mid 4,446.4$ & $(36,330.6$ \\
\hline$(\mathrm{BDT})($ mean $\pm \mathrm{SD})$ & & $40,359.4)$ \\
\hline
\end{tabular}

Table I Background information of participants

Abbreviations: $\mathrm{BDT}$, Bangladeshi Taka (currency); $\mathrm{Cl}$, confidence interval; yrs, years; SD, standard deviation.

with soap for eleven times or more daily. The main reason to skip handwashing was reported as "keep forgetting", which was $52 \%$ and $37.5 \%$ at home and at university, respectively. Approximately $67 \%$ of the respondents said that they had separate soap for washing hand at home and $56 \%$ replied that they used instant hand sterilizer for maintaining hand hygiene. Among the total respondents, $83 \%$ of the students thought that washing hand was important to prevent disease, while $17 \%$ of the students did not think so (Table 2).

With regard to knowledge about handwashing, most of the students $(69 \%)$ believed that cold water should be used for 
Table 2 Attitudes to hand hygiene

\begin{tabular}{|c|c|c|}
\hline Attitudes to hand hygiene & n (\%) & $95 \% \mathrm{Cl}$ \\
\hline \multicolumn{3}{|c|}{ How many times a day do you wash your hands? } \\
\hline Never & I (00.5) & $(0.1,3.5)$ \\
\hline $\mathrm{I}-2$ times & $10(05.0)$ & $(2.7,9.1)$ \\
\hline $3-5$ times & $87(43.5)$ & $(36.7,50.5$ \\
\hline $6-10$ times & $57(28.5)$ & $(22.6,35.2$ \\
\hline II or more & $45(22.5)$ & $(17.2,28.9$ \\
\hline \multicolumn{3}{|c|}{ Reasons for skipping handwashing at home } \\
\hline No need & $62(31.0)$ & $(24.9,37.8$ \\
\hline No available time & $13(06.5)$ & $(3.8,10.9)$ \\
\hline Keep forgetting & $104(52.0)$ & $(45,58.9)$ \\
\hline Far from water and soap & $21(10.5)$ & $(6.9,15.6)$ \\
\hline Poor water supply & $3(0 \mid .5)$ & $(0.5,4.6)$ \\
\hline Others & I (00.5) & $(0.1,3.5)$ \\
\hline \multicolumn{3}{|c|}{ Reasons for skipping handwashing at university } \\
\hline No need & $60(30.0)$ & $(24,36.8)$ \\
\hline No available time & $13(06.5)$ & $(3.8,10.9)$ \\
\hline Keep forgetting & $75(37.5)$ & $(31,44.5)$ \\
\hline Soap not available & $46(23.0)$ & $(I 7.6,29.4$ \\
\hline Poor water supply & $7(03.5)$ & $(1.7,7.2)$ \\
\hline Inadequate facility & $3(01.5)$ & $(0.5,4.6)$ \\
\hline \multicolumn{3}{|c|}{ Separate soap available for handwashing at home } \\
\hline Yes & $135(67.8)$ & $(61,74)$ \\
\hline No & $64(32.2)$ & $(26,39)$ \\
\hline \multicolumn{3}{|c|}{ How often does your household buy soap? } \\
\hline Weekly & $129(64.5)$ & $(57.6,70.9$ \\
\hline I-2 weeks & $9(04.5)$ & $(2.3,8.5)$ \\
\hline $3-4$ weeks & $19(09.5)$ & $(6.1,14.5)$ \\
\hline More than a month & $10(05.0)$ & $(2.7,9.1)$ \\
\hline Do not know & $33(16.5)$ & $(11.9,22.4$ \\
\hline \multicolumn{3}{|c|}{ Do you use instant hand sterilizer when you are outside from home } \\
\hline Yes & $112(56.0)$ & $(49,62.8)$ \\
\hline No & $47(23.5)$ & $(18.1,29.9$ \\
\hline Do not know & $41(20.5)$ & $(I 5.4,26.7$ \\
\hline \multicolumn{3}{|l|}{ How often you cut your nails? } \\
\hline Weekly & $167(83.5)$ & $(77.6,88.1$ \\
\hline I-2 weeks & $15(07.5)$ & $(4.6,12.1)$ \\
\hline 3-4 weeks & $12(06.0)$ & $(3.4,10.3)$ \\
\hline More than a month & $6(03.0)$ & $(1.3,6.6)$ \\
\hline \multicolumn{3}{|l|}{ Toilet facility } \\
\hline Kacha & $5(02.5)$ & $(1,5.9)$ \\
\hline Sanitary & $162(81.0)$ & $(74.9,85.9$ \\
\hline Modern commode & $27(13.5)$ & $(9.4,19)$ \\
\hline Others & $6(03.0)$ & $(1.3,6.6)$ \\
\hline \multicolumn{3}{|l|}{ Toilet facility } \\
\hline Hygienic & $189(94.5)$ & $(90.3,96.9$ \\
\hline Unhygienic & II (05.5) & $(3.1,9.7)$ \\
\hline \multicolumn{3}{|c|}{ Handwashing is important to prevent diseases } \\
\hline Yes & $166(83.0)$ & (77.I, 87.6 \\
\hline No & $34(17.0)$ & $(12.4,22.9$ \\
\hline \multicolumn{3}{|c|}{ Handwashing is a part of personal hygiene } \\
\hline Yes & I 57 (78.5) & $(72.2,83.7$ \\
\hline No & $43(21.5)$ & $(16.3,27.8$ \\
\hline
\end{tabular}

Abbreviation: $\mathrm{Cl}$, confidence interval.

washing hand, while only $28.5 \%$ students replied appropriately that "medium hot water" should be used for washing hand. Approximately $80 \%$ of the respondents answered "watch and bracelets" need to be removed during washing hand and 38.5\% of the students replied that rings need to be removed during handwashing (Table 3). Of the total students, 39.5\% agreed that at least 15 seconds is required for washing hand properly, whereas $26 \%$ respondents disagreed with this question (table not shown). Approximately $30 \%$ of the respondents did not know about the time needed for washing hands.

\section{Hand hygiene practice and its association considering different factors}

Table 4 shows the participants' response of a "handwashing practice checklist" in percentages for every response. The bold numbers indicate the appropriate answer for each type of practice. The mean $( \pm \mathrm{SD})$ score of the participant's hand hygiene practice was $50.81( \pm 4.79)$ (Table 5). Association of handwashing practice with sociodemographic characteristics using " $t$-test" showed statistically significant difference in scores $(P<0.05)$ among marital status where the practice score was higher among the unmarried (51.37) and married (49.34). The result also showed a small variation in the practice score among male (50.64) and female (51.17) students,

Table 3 Knowledge about handwashing

\begin{tabular}{|c|c|c|}
\hline Knowledge about handwashing & n (\%) & $95 \% \mathrm{Cl}$ \\
\hline \multicolumn{3}{|c|}{ What type of water should be used for handwashing? } \\
\hline Cold water & $138(69.0)$ & $(62.2,75.1)$ \\
\hline Medium hot water & $57(28.5)$ & $(22.6,35.2)$ \\
\hline Hot water & $5(2.5)$ & $(1,5.9)$ \\
\hline \multicolumn{3}{|c|}{ How many times are needed for proper handwashing? } \\
\hline Yes & $123(6 \mid .5)$ & $(54.5,68)$ \\
\hline No & $77(38.5)$ & $(32,45.5)$ \\
\hline \multicolumn{3}{|c|}{ With what you should wash your hand? } \\
\hline Only water & $48(24.0)$ & $(18.5,30.5)$ \\
\hline Water with soap & $134(67.0)$ & $(60.1,73.2)$ \\
\hline Water with ash & $16(8.0)$ & $(4.9,12.7)$ \\
\hline Water with mud & $2(1.0)$ & $(0.2,4)$ \\
\hline \multicolumn{3}{|l|}{ Others } \\
\hline \multicolumn{3}{|c|}{ Watch and bracelet should be removed during handwashing? } \\
\hline Yes & $162(81.0)$ & $(74.9,85.9)$ \\
\hline No & $38(19.0)$ & $(14.1,25.1)$ \\
\hline \multicolumn{3}{|c|}{ Rings should be removed during handwashing? } \\
\hline Yes & $137(68.5)$ & $(61.7,74.6)$ \\
\hline No & $53(26.5)$ & $(20.8,33.1)$ \\
\hline Do not know & $10(5.0)$ & $(2.7,9.1)$ \\
\hline \multicolumn{3}{|c|}{ Wrist should be washed during handwashing? } \\
\hline Yes & $145(72.5)$ & $(65.8,78.3)$ \\
\hline No & $18(9.0)$ & $(5.7,13.9)$ \\
\hline Do not know & $37(18.5)$ & $(13.7,24.5)$ \\
\hline \multicolumn{3}{|c|}{ Hands need to be dried after washing } \\
\hline Yes & $160(80.0)$ & $(73.8,85.0)$ \\
\hline No & $29(14.5)$ & $(10.2,20.1)$ \\
\hline Do not know & I I (5.5) & $(3.1,9.7)$ \\
\hline
\end{tabular}

Abbreviation: $\mathrm{Cl}$, confidence interval. 
Table 4 Practice toward handwashing

\begin{tabular}{|c|c|c|c|}
\hline Handwashing practice & Always, n (\%) & Sometimes, n (\%) & Never, n (\%) \\
\hline Before meals & $197(98.5)$ & $03(0 \mathrm{I} .5)$ & - \\
\hline After meals & $183(9 \mid .5)$ & $17(08.5)$ & - \\
\hline After coming from toilet & $176(88.0)$ & $22(11.0)$ & $02(0 \mathrm{I} .0)$ \\
\hline With water and soap & $177(88.5)$ & $22(11.0)$ & 이 (00.5) \\
\hline When come home & $167(83.5)$ & $31(15.5)$ & $02(01.0)$ \\
\hline After handshaking & $143(7 \mid .5)$ & $50(25.0)$ & $07(03.5)$ \\
\hline Before going to bed & $|3|(65.5)$ & $63(31.5)$ & $06(03.0)$ \\
\hline After using public transportation & $154(77.0)$ & $43(21.5)$ & $03(0 \mathrm{I} .5)$ \\
\hline After waking up in the morning & $117(58.5)$ & $74(37.0)$ & $09(04.5)$ \\
\hline After touching animals & $138(69.0)$ & $57(28.5)$ & $05(02.5)$ \\
\hline Only if they are soiled & $126(63.0)$ & $63(31.5)$ & I I (05.5) \\
\hline Before preparing meals & $148(74.0)$ & $42(21.0)$ & $10(05.0)$ \\
\hline After money exchange & $137(68.5)$ & $54(27.0)$ & $09(04.5)$ \\
\hline After blowing the nose & $145(72.5)$ & $52(26.0)$ & $03(0 \mathrm{I} .5)$ \\
\hline After touching garbage & $|3|(65.5)$ & $63(31.5)$ & $06(03.0)$ \\
\hline Before touching sick people & $128(64.0)$ & $66(33.0)$ & $06(03.0)$ \\
\hline After touching sick people & $137(68.5)$ & $58(29.0)$ & $05(02.5)$ \\
\hline After combing my hair & I I I (55.5) & $72(36.0)$ & $17(08.5)$ \\
\hline After cleaning my home & $134(67.0)$ & $38(19.0)$ & $28(14.0)$ \\
\hline After washing dishes & $098(49.0)$ & $38(19.0)$ & $64(32.0)$ \\
\hline After doing laundry & $07 \mid(35.5)$ & $33(16.5)$ & $96(48.0)$ \\
\hline
\end{tabular}

Notes: Bold values indicate correct answer. '-' indicates the number of responses is zero in terms of "never practiced" in response to the question.

but statistically, it was not a significant difference $(P>0.05)$ (Table 5). Handwashing practice with some sociodemographic characteristics using "one-way analysis of variance test" showed that the mean score varies with department, which is statistically significant $(P<0.05)$. The result also showed that a small variation in the practice score related with living conditions, and the difference is statistically significant $(P<0.05)$. The practice level of hand hygiene was higher among those who lived with family (51.6) compared to others and the lowest among those who lived alone (45.00).

\section{Factors associated with hand hygiene practice}

Table 6 shows the results of multiple regression analysis that analyzes the effect of handwashing practice score by demographic

Table 5 Participants' handwashing practice score based on some sociodemographic features

\begin{tabular}{lccccccc}
\hline $\begin{array}{l}\text { Name of the } \\
\text { variable }\end{array}$ & $\mathbf{n}$ & Mean & $\%$ & SD & SE & $95 \% \mathbf{C l}$ & P-value \\
\hline $\begin{array}{l}\text { Practice score } \\
\text { Sex }\end{array}$ & 200 & $50.8 \mathrm{I}$ & 80.6 & 4.79 & 0.33 & $50.1-5 \mathrm{I} .4$ & 0.000 \\
$\begin{array}{l}\text { Male } \\
\text { Female }\end{array}$ & $\mathrm{I} 37$ & 50.64 & 80.3 & 4.85 & $0.4 \mathrm{I}$ & $49.8-5 \mathrm{I} .4$ & 0.470 \\
$\begin{array}{l}\text { Marital status } \\
\text { Married }\end{array}$ & 63 & $5 \mathrm{I} . \mathrm{I} 7$ & $8 \mathrm{I} .2$ & 4.65 & 0.58 & $50.1-52.3$ & \\
Unmarried & $\mathrm{I} 45$ & 59.34 & 78.3 & 4.88 & 0.65 & $50.0-53.0$ & 0.007 \\
\hline
\end{tabular}

Note: $P$-value was derived from independent $t$-test.

Abbreviations: $\mathrm{SD}$, standard deviation; $\mathrm{SE}$, standard error; $\mathrm{Cl}$, confidence interval. and socioeconomic characteristics. The regression model explains $43.1 \%$ of total variations $\left(R^{2}=0.431\right)$. The Breusch-Pagan/CookWeisberg test showed that heteroscedasticity was not present in the model. Variance inflation factor test with its mean (max) value of 2.4 (4.70) indicates that there is no evidence of multicollinearity problem in the regression model. ${ }^{17}$ Ramsey regression equation specification error test (RESET) showed that there was sufficient evidence against the hypothesis of omitted variable bias in the model. Regression coefficient demonstrated that age has a negative influence on hand hygiene practice as older students had lower scores compared to the younger ones $(P<0.01)$. On the contrary, marital status showed that the unmarried students were influencing the incensement of handwashing practice more than the married students $(P<0.01)$. The level of higher grade education of participants had also played a significant impact on handwashing practices compared to that of lower grade education.

Conversely, the lower grade of mother education level was negatively associated with the handwashing practice than the higher level of education (Table 6). On the contrary, the sex of the participating students, father's education level, as well as the current living conditions were not significant predictors of handwashing practice.

\section{Discussion}

The present study attempted to assess hand hygiene knowledge and practice among private university students of Bangladesh. It also determined the associations with some 
sociodemographic features and provided several significant findings. The results of the study indicate that most of the respondents maintained hand hygiene but not sufficiently enough to prevent infection. In this study, most of the participants washed their hands three to five times a day, which is an insufficient number for proper hand hygiene. In contrast, majority of the respondents had separate soap for hand wash in their homes; it is also promising that the majority use instant hand sterilizer when they are outside of home or if water or soap is not available. Our study also indicated that the main reasons for skipping handwashing at home, and in the university setting were participants' beliefs on "keep forgetting", "no need", and poor water supply. Another study encompassing health workers inquired about the reasons for not washing their hands and they pointed out similar attitudes such as "not think about it at the moment", "forgetting", and "being

Table 6 Effect of hand hygiene practice score on different factors

\begin{tabular}{|c|c|c|c|c|}
\hline \multirow[t]{2}{*}{ Variables } & \multirow{2}{*}{$\begin{array}{l}\text { Practice score } \\
\text { (mean } \pm \text { SD) }\end{array}$} & \multirow{2}{*}{$\begin{array}{l}\text { Model I } \\
\text { Unadjusted coefficient }(95 \% \mathrm{CI})\end{array}$} & \multicolumn{2}{|l|}{ Model 2} \\
\hline & & & Adjusted coefficient ( $95 \% \mathrm{CI})$ & VIF \\
\hline Constant & & & $53.8 * * *(50.9,56.6)$ & \\
\hline \multicolumn{5}{|l|}{ Age group } \\
\hline$<19$ years (ref) & $54.9 \pm 3.6$ & - & - & - \\
\hline $19-20$ years & $53.2 \pm 5.06$ & $-I .7 \mid(-3.7,0.24)$ & $-1.4(-3.23,0.42)$ & 2.9 \\
\hline $21-22$ years & $51.5 \pm 4.61$ & $-3.5^{* * *}(-5.6,-\mid .31)$ & $-2.3^{* *}(-4.7,-0.1)$ & 3.5 \\
\hline$\geq 23$ years & $51.4 \pm 4.8$ & $-3.5^{* * *}(-5.9,-0.9)$ & $-4.2^{* * *}(-7.7,-0.6)$ & 4.7 \\
\hline \multicolumn{5}{|l|}{ Sex } \\
\hline Male (ref) & $52.6 \pm 4.9$ & - & - & - \\
\hline Female & $53.1 \pm 4.7$ & $0.5^{* *}(-0.9,2.0)$ & $0.1(-I .2, I .5)$ & $\mathrm{I} .4$ \\
\hline \multicolumn{5}{|l|}{ Marital status } \\
\hline Married (ref) & $51.3 \pm 5.0$ & - & - & - \\
\hline Unmarried & $53.4 \pm 4.7$ & $2.1 * * *(0.6,3.6)$ & $1.9 * * *(0.5,3.3)$ & 1.3 \\
\hline \multicolumn{5}{|l|}{ Educational status } \\
\hline First year (ref) & $51.6 \pm 5.2$ & - & - & - \\
\hline Second year & $53.4 \pm 4.9$ & $1.8 * *(-0.2,3.9)$ & I.7 (-0.2, 3.7) & 3.3 \\
\hline Third year & $52.7 \pm 4.6$ & I.I (-I.2, 3.4) & 3.I*** $(0.8,5.5)$ & 2.9 \\
\hline Fourth year & $52.0 \pm 4.6$ & $0.4 \mathrm{I}(-2.0,2.9)$ & $3.4 * *(-0.0,6.7)$ & 4.2 \\
\hline \multicolumn{5}{|l|}{ Mother's education } \\
\hline Up to primary & $48.3 \pm 3.7$ & $-7.1 * * *(-9.0,-5.3)$ & $-6.1^{* * *}(-8.7,-3.4)$ & 3.2 \\
\hline Secondary & $50.3 \pm 4.6$ & $-5.1 * * *(-6.8,-3.4)$ & $-5.2^{* * *}(-7.5,-2.9)$ & 3.2 \\
\hline Higher secondary & $54.5 \pm 3.8$ & $-I(-2.5,0.5)$ & $-1.9 * *(-3.5,-0.2)$ & 2.4 \\
\hline Higher & $55.5 \pm 4.1$ & - & - & - \\
\hline \multicolumn{5}{|l|}{ Father's education } \\
\hline Up to primary & $48.4 \pm 4.0$ & $-5.7 * * *(-7.8,-3.5)$ & $-1.69(-4.1,0.7)$ & 1.9 \\
\hline Secondary & $50.3 \pm 4.1$ & $-3.8 * * *(-6.0,-1.6)$ & $-0.02(-2.3,2.3)$ & $\mathrm{I} .7$ \\
\hline Higher secondary & $53.2 \pm 4.0$ & $-0.87(-2.3,0.5)$ & $0.83(-0.8,2.5)$ & 2.3 \\
\hline Higher (ref) & $54.1 \pm 4.2$ & - & - & - \\
\hline \multicolumn{5}{|l|}{ Household size, n } \\
\hline$<4$ (ref) & $51.3 \pm 4.5$ & - & - & - \\
\hline $4-5$ & $53.1 \pm 5.0$ & I.80** $(-0.0,3.7)$ & $0.64(-1.0,2.2)$ & 1.6 \\
\hline$>5$ & $53.3 \pm 3.9$ & $2.06(-0.8,5.0)$ & $2.78(0.3,5.3)$ & 1.6 \\
\hline \multicolumn{5}{|l|}{ Living condition } \\
\hline With family (ref) & $53.6 \pm 4.4$ & - & - & - \\
\hline With relatives & $51.1 \pm 5.6$ & $-2.4 * *(-4.4,-0.4)$ & $-I . I(-2.8,0.63)$ & 1.2 \\
\hline Hostel or with friends & $52.1 \pm 5.1$ & $-1.45^{* *}(-3.0,0.1)$ & $-0.7(-2,0.7)$ & 1.2 \\
\hline Others & $51.0 \pm 4.7$ & $-2.6(-6.9,1.8)$ & $-0.5(-4.2,3.2)$ & 1.2 \\
\hline$R^{2}$ & & & 0.431 & \\
\hline F-Statistics & & & $6.78 * * *$ & \\
\hline Mean (VIF) & & & 2.4 & \\
\hline Ramsey RESET & & & $3.72 * * *$ & \\
\hline Breusch-Pagan/Cook-V & erg test & & $\chi^{2}(I)=2.4 I$ & \\
\hline
\end{tabular}

Notes: *** \% level of significance. **5\% level of significance.

Abbreviations: SD, standard deviation; $\mathrm{Cl}$, confidence interval; VIF, variance inflation factor; ref, reference; RESET, regression equation specification error test. 
busy". ${ }^{18}$ Other relevant studies on handwashing showed that "skin drying effect of hand hygiene products, soap or paper towels unavailability", "lack of time", "lack of knowledge", "not thought and forgotten", and "lack of role models in school or among adults" were the main obstacles in promoting handwashing as the habit of proper hand hygiene. ${ }^{18,19}$

Regression analysis showed no significant variation in the hand hygiene practice among sexes, but it showed significant difference in the marital status, where the hand hygiene practice score was more among the unmarried students. A previous study on the topic did not show any difference between males and females, which is similar to a study done in Africa. However, the study from Africa did not show any difference in the frequency of handwashing between sexes. ${ }^{20}$ Participants' faculty was also associated with the scores in the current study. Our study also showed that handwashing practice is associated with the living condition of the participants and is significantly higher among those who live with their family. This study found that the level of education had a significant impact on handwashing practices and that higher grade students practice handwashing frequently than the lower grade students, indicating that the university-based hygiene education is also vital in order to decrease the rates of transmissible diseases. ${ }^{21}$

\section{Limitations}

There are several limitations to this study. As the survey was restricted to the undergraduate students of the selected private university in urban Dhaka, it does not reflect Bangladeshi population as a whole and also does not represent all university students of the country. The participants were quite homogenous as a group, and so it was impossible to compare knowledge about and attitudes toward hand hygiene with regard to the sociodemographic context. Future nationwide research is needed to address these issues.

\section{Conclusion}

The findings of this study may indicate widespread insufficient hand hygiene in the university-going population. Moreover, low scores related to participants' handwashing knowledge and practice may indicate a need for an extensive public health education program on the topic. The hand hygiene awareness and compliance among the university students were found to be relatively low. The study shows the need for further improvement in the existing hand hygiene behavioral change communication programs to address the gaps in knowledge, attitudes, and practices. Furthermore, multifaceted and dedicated efforts must be undertaken to rectify this attitude and behavior from early on. Therefore, supporting quantity and/or quality of the available campusbased public health education programs and development of hand hygiene promotion programs for the general public based on the findings of this study are recommended.

\section{Acknowledgments}

We gratefully acknowledge Government of the People's Republic of Bangladesh; the Department of Foreign Affairs, Trade and Development, Canada; Swedish International Development Cooperation Agency (Sida); and the Department for International Development (UK Aid) for their unrestricted support and commitment to the International Centre for Diarrhoeal Disease Research, Bangladesh's research efforts. The authors would also like to thank all the participating students.

\section{Disclosure}

The authors report no conflicts of interest in this work.

\section{References}

1. Burton M, Cobb E, Donachie P, Judah G, Curtis V, Schmidt WP. The effect of handwashing with water or soap on bacterial contamination of hands. Int J Environ Res Public Health. 2011;8:97-104.

2. Tao SY, Cheng YL, Lu Y, Hu YH, Chen DF. Handwashing behaviour among Chinese adults: a cross-sectional study in five provinces. Public Health. 2013;127:620-628.

3. WHO. Risk Factors Influencing Children's Healthy Environment in Kaplamai Division Trans-Nzoia District. Baseline Survey Report. Geneva: WHO; 2010.

4. Aiello AE, Larson EL. Causal inference: the case of hygiene and health. Am J Infect Control. 2002;30:503-510.

5. Aiello AE, Larson EL. What is the evidence for a causal link between hygiene and infections? Lancet Infect Dis. 2002;2:103-110.

6. Ergin A, Ergin N. Evaluation of student's social handwashing knowledge, practices, and skills in a university setting. Cent Eur J Public Health. 2011;19:222-227.

7. Matthews Z. World Health Report 2005: Make Every Mother and Child Count. Vol. 33. Geneva: World Health Report; 2005:409-411.

8. Luby SP, Agboatwalla M, Feikin DR, et al. Effect of handwashing on child health: a randomised controlled trial. Lancet. 2005;366:225-233.

9. White C, Kolble R, Carlson R, et al. The effect of hand hygiene on illness rate among students in university residence halls. Am J Infect Control. 2003;31:364-370.

10. Rabbi SE, Dey NC. Exploring the gap between handwashing knowledge and practices in Bangladesh: a cross-sectional comparative study. BMC Public Health. 2013;13:89.

11. Aiello AE, Coulborn RM, Perez V, Larson EL. Effect of hand hygiene on infectious disease risk in the community setting: a meta-analysis. Am J Public Health. 2008;98:1372-1381.

12. Curtis V, Cairncross S. Reviews effect of washing hands with soap on diarrhoea risk in the community: a systematic review. Lancet Infect Dis. 2003;3:275-281

13. Halder AK, Tronchet C, Akhter S, Bhuiya A, Johnston R, Luby SP. Observed hand cleanliness and other measures of handwashing behavior in rural Bangladesh. BMC Public Health. 2010;10:1-9.

14. Luby SP, Halder AK, Huda T, Unicomb L, Johnston RB. The effect of handwashing at recommended times with water alone and with soap on child diarrhea in rural Bangladesh: an observational study. PLoS Med. 2011;8:e1001052. 
15. Miko BA, Cohen B, Conway L, Gilman A, Seward SL Jr, Larson E. Determinants of personal and household hygiene among college students in New York City, 2011. Am J Infect Control. 2012;40:940-945.

16. Anderson JL, Warren CA, Perez E, et al. Gender and ethnic differences in hand hygiene practices among college students. Am J Infect Control. 2008;36:361-368.

17. Hossain M, Saw A, Alam R, Ohtsuki F, Kamarul T. Multiple regression analysis of anthropometric measurements influencing the cephalic index of male Japanese university students. Singapore Med J. 2013;54:516-520.
18. Pittet D, Mourouga P, Perneger TV. Compliance with handwashing in a teaching hospital. Infection control program. Ann Intern Med. 1999;130:126-130.

19. Larson EL, Bryan JL, Adler LM, Blane C. A multifaceted approach to changing handwashing behavior. Am J Infect Control. 1997;25:3-10.

20. Adjuik M, Smith T, Clark S, et al. Cause-specific mortality rates in sub-Saharan Africa and Bangladesh. Bull World Health Organ. 2006;84:181-188.

21. Lopez-Quintero C, Freeman P, Neumark Y. Hand washing among school children in Bogotá, Colombia. Am J Public Health. 2009;99:94-101.

\section{Publish your work in this journal}

Risk Management and Healthcare Policy is an international, peerreviewed, open access journal focusing on all aspects of public health, policy, and preventative measures to promote good health and improve morbidity and mortality in the population. The journal welcomes submitted papers covering original research, basic science, clinical \& epidemio- logical studies, reviews and evaluations, guidelines, expert opinion and commentary, case reports and extended reports. The manuscript management system is completely online and includes a very quick and fair peerreview system, which is all easy to use. Visit http://www.dovepress.com/ testimonials.php to read real quotes from published authors. 